\title{
PERAN KADER KESEHATAN JIWA DALAM MELAKUKAN PENANGANAN GANGGUAN JIWA
}

\author{
Dwi Indah Iswanti ${ }^{1}$, Sri Puji Lestari ${ }^{1}$, Ria Dwi Hapsari ${ }^{1}$ \\ ${ }^{1}$ STIKES Karya Husada Semarang \\ Email: misskey.indah@yahoo.com
}

\begin{abstract}
ABSTRAK
Gangguan jiwa merupakan manifestasi dari bentuk penyimpangan perilaku akibat adanya distorsi emosi sehingga ditemukan ketidakwajaran dalam bertingkah laku. Hal ini terjadi karena menurunnya semua fungsi kejiwaan. Menurut data World Health Organization sebanyak 35 juta orang terkena depresi, 60 juta orang terkena bipolar, 47,5 juta terkena dimensia dan 21 juta terkena skizofrenia. Mengeksplorasi peran kader kesehatan jiwa dalam penanganan pasien gangguan jiwa di RW 06 Kelurahan Gemah Kota Semarang. Penelitian kualitatif dengan pendekatan fenomenologi. Partisipan menggunakan 3 (tiga) Kader Kesehatan Jiwa di RW 06 Kelurahan Gemah Kota Semarang. Peran Kader Kesehatan Jiwa dalam penyuluhan dengan melakukan pendekatan pada keluarga yang mengidap gangguan jiwa, dan melaksanakan pemantauan perkembangan individu dengan gangguan jiwa. Melakukan kegiatan TAK dan rehabilitasi sesuai dengan prosedur pelaksanaan. Memberikan informasi untuk menggerakkan keluarga untuk melakukan rujukan pada pasien dengan gangguan gangguan jiwa. Melakukan pendokumentasian sesuai dengan lembar observasi yang sudah tersedia.
\end{abstract}

Kata Kunci : Peran; Kader Kesehatan Jiwa; Penanganan Pasien

\section{THE ROLE OF MENTAL HEALTH CADRES IN THE HANDLING OF MENTAL PATIENTS}

\begin{abstract}
Mental disorder is a manifestation of the form of behavioral aberrations due to emotional distortion to the point that there is an irregularity in behavior. This happens because of the decline in all psychological functions. According to World Health Organization data of 35 million people affected by depression, 60 million people exposed to bipolar, 47.5 million exposed to dementia and 21 million exposed to schizophrenia. Exploration study on the role of mental health cadres in the handling of mental patients in $R W 06$ Kelurahan Gemah Semarang City. The research method used qualitative research with phenomenology approach. Participants in this study is 3 (three) of mental health cadres. The roles of mental health cadres for health counseling in RW 06 Kelurahan Gemah Semarang City by collecting data on people with mental disorders, recording individuals with mental disorders, getting approval from families to obtain information and carry out monitoring the development of individuals with mental disorders. TAK and rehabilitation activities require a strategic approach by following procedures in the implementation of TAK, Providing information to mobilize families to conduct referrals in patients with mental disorders and recording and documenting the development of mental health in the available observation sheets.
\end{abstract}

Keywords: Roles; Mental Health Cadres; Patient Handling

\section{PENDAHULUAN}

Gangguan jiwa merupakan manifestasi dari bentuk penyimpangan perilaku akibat adanya distorsi emosi sehingga ditemukan ketidakwajaran dalam bertingkah laku, hal ini terjadi karena menurunnya semua fungsi kejiwaan (Kristiati, dkk, 2016). Menurut data World Health Organization sebanyak 35 juta orang terkena depresi, 60 juta orang terkena bipolar, 47,5 juta terkena dimensia dan 21 juta terkena skizofrenia. Berdasar data dari Dinas Kesehatan Kota Jawa Tengah (2015) angka kejadian penderita gangguan jiwa di Jawa Tengah berkisar 317.504 orang jumlah pasien gangguan jiwa mengalami peningkatan sebelumnya pada 2013 sebanyak 121.962 dan tahun 2014 menjadi 260.247 penderita. Hasil penelitian lain oleh Windarwati, Lestari, Hany (2013) pemberdayaan masyarakat berbasis 
keperawatan kesehatan jiwa dalam upaya peningkatan kualitas kesehatan jiwa ibu dan anak di Kecamatan Bantur dan Wager Kabupaten Malang menunjukkan pelaksanaan pelatihan SDM CMHN menunjukkan adanya sustainability kemampuan puskesmas dalam melakukan upaya pelayanan kesehatan jiwa. Di masyarakat pasien gangguan jiwa memerlukan pendekatan strategi melibatkan masyarakat diawasi petugas kesehatan. Departemen kesehatan berupaya memfasilitasi percepatan pencapaian derajat kesehatan setinggi-tingginya bagi seluruh penduduk dengan mengembangkan kesiapsiagaan di tingkat desa (Nasir \& Abdul, 2011).

Hasil wawancara dengan 4 kader kesehatan jiwa di RW 06, hasilnya keempat kader sudah dilatih oleh RSJD Dr. Amino Gondohutomo, peran kader saat ini adalah melakukan deteksi dini pada warga yang mengalami gangguan jiwa, peran lain yang dilakukan kader yaitu memberikan penyuluhan kesehatan pada saat pertemuan PKK dan Dasa Wisma, sementara peran kader yang lain belum dilakukan.Berdasarkan uraian latar belakang diatas, maka fokus penelitian ini adalah tentang: "Peran Kader Kesehatan Jiwa Dalam Melakukan Penanganan Pasien Gangguan Jiwa di RW 06 Kelurahan Gemah Kota Semarang, meliputi: penyuluhan kesehatan, kunjungan rumah, kegiatan TAK dan rehabilitasi, upaya rujukan dan dokumentasi kegiatan".

\section{METODE}

Gangguan jiwa merupakan manifestasi dari bentuk penyimpangan perilaku akibat adanya distorsi emosi sehingga ditemukan ketidakwajaran dalam bertingkah laku, hal ini terjadi karena menurunnya semua fungsi kejiwaan (Kristiati, dkk, 2016).

Menurut data World Health Organization sebanyak 35 juta orang terkena depresi, 60 juta orang terkena bipolar, 47,5 juta terkena dimensia dan 21 juta terkena skizofrenia. Berdasar data dari Dinas Kesehatan Kota Jawa Tengah (2015) angka kejadian penderita gangguan jiwa di Jawa Tengah berkisar 317.504 orang jumlah pasien gangguan jiwa mengalami peningkatan sebelumnya pada 2013 sebanyak 121.962 dan tahun 2014 menjadi 260.247 penderita. Hasil penelitian lain oleh Windarwati, Lestari, Hany (2013) pemberdayaan masyarakat berbasis keperawatan kesehatan jiwa dalam upaya peningkatan kualitas kesehatan jiwa ibu dan anak di Kecamatan Bantur dan Wager Kabupaten Malang menunjukkan pelaksanaan pelatihan SDM CMHN menunjukkan adanya sustainability kemampuan puskesmas dalam melakukan upaya pelayanan kesehatan jiwa. Di masyarakat pasien gangguan jiwa memerlukan pendekatan strategi melibatkan masyarakat diawasi petugas kesehatan. Departemen kesehatan berupaya memfasilitasi percepatan pencapaian derajat kesehatan setinggi-tingginya bagi seluruh penduduk dengan mengembangkan kesiapsiagaan di tingkat desa (Nasir \& Abdul, 2011).

Hasil wawancara dengan 4 kader kesehatan jiwa di RW 06, hasilnya keempat kader sudah dilatih oleh RSJD Dr. Amino Gondohutomo, peran kader saat ini adalah melakukan deteksi dini pada warga yang mengalami gangguan jiwa, peran lain yang dilakukan kader yaitu memberikan penyuluhan kesehatan pada saat pertemuan PKK dan Dasa Wisma, sementara peran kader yang lain belum dilakukan.Berdasarkan uraian latar belakang diatas, maka fokus penelitian ini adalah tentang: "Peran Kader Kesehatan Jiwa Dalam Melakukan Penanganan Pasien Gangguan Jiwa di RW 06 Kelurahan Gemah Kota Semarang, meliputi: penyuluhan kesehatan, kunjungan rumah, kegiatan TAK dan rehabilitasi, upaya rujukan dan dokumentasi kegiatan".

\section{HASIL}

Partisipan penelitian berumur berkisar antara 20-35 tahun. Dimana kelompok umur tersebut tergolong usia dewasa awal dengan fase tugas perkembangan keluarga merawat anak. Biasanya keluarga berupaya memberikan perhatian, merawat anak dengan sebaikbaiknya dan memberikan perawatan dan memperhatikan pendidikan bagi buah hatinya. Ketika anak sakit keluarga berupaya memberikan perawatan yang terbaik dengan membawa ke pusat pelayanan kesehatan seperti Rumah Sakit.

Pendidikan partisipan seluruhnya adalah masuk dalam kategori pendidikan menengah. Berdasarkan tingkat pendidikan partisipan sangat dimungkinkan bahwa pengetahuannya tentang kesehatan jiwa dan peran kader kesehatan jiwa cukup baik. 


\section{PEMBAHASAN}

Peran kader kesehatan jiwa dalam melakukan penyuluhan kesehatan

Hasil penelitian tentang peran kader kesehatan jiwa dalam penyuluhan para partisipan umumnya memberikan jawaban bahwa kegiatan penyuluhan adalah melakukan pendataan keluarga yang mengalami gangguann jiwa, melaporkan dan melakukan penyuluhan saat kegiatan posyandu, di arisan PKK dan penyuluhan dengan kerjasama dengan pihak RSJ. Hal ini sesuai dengan jawaban triangulasi bahwa kegiatan penyuluhan kader kesehatan jiwa adalah telah melakukan penyuluhan kepada ibu-ibu melalui arisan PKK.

Pemberdayaan kader kesehatan jiwa sebagai tenaga potensial yang ada di masyarakat diharapkan mampu mendukung program CMHN yang diterapkan di masyarakat (Nasir \& Abdul, 2011). Pengembangan kemampuan kader kesehatan jiwa merupakan salah satu proses yang berhubungan dengan manajemen SDM. Pengembangan kader kesehatan jiwa di Desa Siaga Sehat Jiwa dilakukan melalui kegiatan penyegaran kader atau pelatihan lanjutan (Sugiyono, 2012).

\section{Peran kader kesehatan jiwa dalam melakukan kunjungan rumah}

Hasil penelitian tentang peran kader kesehatan jiwa dalam kunjungan para partisipan umumnya memberikan jawaban bahwa melakukan persetujuan dan pendekatan dan selanjutnya bertanya cara merawat pasien gangguan jiwa. Pemahaman partisipan tentang peran kader kesehatan dalam melakukan kunjungan rumah adalah kegiatan melakukan cara merawat anggota keluarga yang mengalami gangguan jiwa. Hal ini sesuai dengan triangulasi teori bahwa peran kader kesehatan dalam kunjungan dilakukan untuk memperoleh informasi terkini tentang kemampuan pasien mengatasi masalahnya dan keterlibatan keluarga dalam perawatan pasien di rumah (Nasir \& Abdul, 2011). Pernyataan partisipan diperkuat juga oleh triangulasi sumber kegiatan kader kesehatan jiwa dalam kunjungan rumah adalah sebagai berikut: pendekatan terlebih dahulu kemudian meminta ijin kepada keluarganya. Paling tidak sebulan sekali kader melakukan kunjungan rumah bila tidak memungkinkan ya sesempetnya aja, kami sampaikan kalau berkunjung ditanyakan keadaan pasien bagaimana, bisa kah keluarga merawat pasien tersebut, bagaimana minum obatnya, apakah rutin untuk kontrol ke RSJ (T1).

Kunjungan rumah dilakukan untuk memperoleh informasi terkini tentang kemampuan pasien mengatasi masalahnya dan keterlibatan keluarga dalam perawatan pasien di rumah. Kader kesehatan jiwa akan melakukan serah terima dengan perawat CMHN dan kader kesehatan jiwa akan memantau perkembangan pasien dengan menggunakan buku supervisi pasien.

\section{Peran kader kesehatan jiwa dalam melakukan kegiatan TAK dan rehabilitasi}

Hasil penelitian tentang peran kader kesehatan jiwa dalam kegiatan TAK para partisipan umumnya memberikan jawaban bahwa kegiatan kegiatan TAK adalah kader hanya mengumpulkan para warga dan yang akan melakukan adalah dari petugas RSJ. Pelaksanaan kegiatan yang dilakukan dalam menggerakkan kelompok pasien gangguan jiwa untuk mengikuti TAK dan rehabilitasi adalah kader mengumpulkan peserta TAK dan rehabilitasi serta memotivasi peserta untuk aktif dan kader mendampingi perawat $\mathrm{CMHN}$ yang melakukan kegiatan TAK dan rehabilitasi. Pernyataan partisipan diperkuat oleh triangulasi sumber kegiatan kader kesehatan jiwa dalam kegiatan TAK adalah sebagai berikut: Pihak dari kami (RSJ) yang melakukan kader yang mengumpulkan warga dan mencari tempat untuk pelaksanaannya, dari situ kader bisa melihat bagaimana sistematis pelaksanaan dari TAK (T1).

Perawatan kesehatan mental di Indonesia masih jauh dari standar negara maju. Banyak orang dengan penyakit jiwa tidak memiliki akses terhadap layanan kesehatan mental. Pelayanan kesehatan primer tidak mengutamakan masalah kesehatan mental. Keterampilan dokter kesehatan primer tidak begitu bagus. Kualitas pelayanan kesehatan mental di rumah sakit umumnya buruk, dan pengobatan konvensional seperti pemberian psikotik khas tanpa perawatan lainnya sangat dominan di rumah sakit jiwa.

Peran kader kesehatan jiwa dalam melakukan upaya rujukan 
Hasil penelitian tentang peran kader kesehatan jiwa dalam rujukan para partisipan umumnya memberikan jawaban bahwa kegiatan rujukan adalah mendata pasien yang mengalami gangguan jiwa dengan gejala marah-marah, kemudian kader lapor ke Puskesmas dan yang merujuk ke RSJ adalah dari pihak Puskesmas. Pernyataan partisipan diperkuat oleh triangulasi sumber kegiatan kader kesehatan jiwa dalam kegiatan rujukan adalah sebagai berikut kami telah sampaikan ke kader untuk dapat mengetahui rentang dari yang sehat hingga mengalami gangguan. Sehingga kader dapat mengetahui mana saja yang dianggap untuk bisa dilakukan rujukan ke RSJ. Kader harus menghubungi pihak Puskesmas untuk mendapatkan pendampingan (T1).

Pemahaman partisipan tentang peran kader kesehatan dalam melakukan kegiatan rujukan adalah bahwa kader kesehatan jiwa setelah mendapatkan warganya ada gejala gangguan jiwa maka kader kesehatan jiwa akan menghubungi petugas Puskesmas dan nantinya petugas Puskesmas yang akan merujuk ke RSJ. Pengembangan kemampuan kader kesehatan jiwa merupakan salah satu proses yang berhubungan dengan manajemen sumber daya manusia. Tujuan pengembangan tenaga kader kesehatan jiwa akan membantu masing-masing kader mencapai kinerja sesuai dengan posisinya dan sebagai penghargaan terhadap kinerja yang telah dicapai (Keliat, dkk, 2011).

\section{Peran kader kesehatan jiwa dalam melakukan dokumentasi}

Hasil penelitian tentang peran kader kesehatan jiwa dalam dokumentasi para partisipan umumnya memberikan jawaban bahwa kegiatan dokumentasi adalah kader akan melakukan pencatatan kegiatannya dengan menggunakan form yang sudah diberikan oleh pihak RSJ. Pernyataan partisipan diperkuat oleh triangulasi sumber kegiatan kader kesehatan jiwa dalam kegiatan rujukan adalah sebagai berikut Kami mewajibkan kader untuk melaporkan semua kegiatannya yang berhubungan dengan kesehatan jiwa, kami sudah memberikan form yang sebelumnya sudah kami pandu tentang bagaimana cara mengisinya (T1).

Pemahaman partisipan tentang peran kader kesehatan dalam melakukan kegiatan dokumentasi adalah bahwa kader kesehatan jiwa mencatat kegiatan di Kelurahan Gemah dengan format yang sudah disediakan oleh RSJ. Hal ini sesuai dengan yang diungkapkan oleh triangulasi sumber dan teori pendokumentasian adalah menuliskan seluruh tindakan yang dilakukan kader dengan menggunakan panduan pelaporan yang tersedia (Nasir \& Abdul, 2011). Setelah mengikuti pelatihan, kader kesehatan jiwa diharapkan mampu memahami keperawatan kesehatan jiwa di masyarakat, memahami kebijakan kesehatan jiwa di masyarakat, memahami Desa Siaga Sehat Jiwa di masyarakat, melakukan deteksi dini masalah kesehatan jiwa, menggerakkan individu, keluarga, kelompok sehat jiwa, kelompok resiko dan kelompok gangguan jiwa, melakukan rujukan kasus masalah psikososial atau gangguan jiwa pada perawat CMHN (Community Mental Health Nursing) di Puskesmas, serta melakukan pencatatan dan pelaporan kegiatan kader kesehatan jiwa (Keliat, dkk, 2010).

\section{SIMPULAN DAN SARAN \\ Simpulan}

Peran kader kesehatan jiwa dalam penyuluhan para partisipan umumnya memberikan jawaban bahwa kegiatan penyuluhan adalah menggerakkan keluarga sehat, resiko psikososial dan gangguan jiwa untuk menghadiri penyuluhan sesuai dengan usia. Peran kader kesehatan dalam melakukan kunjungan rumah adalah kegiatan melakukan cara merawat anggota keluarga yang mengalami gangguan jiwa. Peran kader kesehatan dalam melakukan kegiatan TAK adalah bahwa kader kesehatan jiwa diberi tugas untuk mengumpulkan warga dan yang melakukan kegiatan TAK adalah petugas dari RSJ. Peran kader kesehatan dalam melakukan kegiatan rujukan adalah bahwa kader kesehatan jiwa setelah mendapatkan warganya ada gejala gangguan jiwa maka kader kesehatan jiwa akan menghubungi petugas Puskesmas dan nantinya petugas Puskesmas yang akan merujuk ke RSJ. Peran kader kesehatan dalam melakukan kegiatan dokumentasi adalah bahwa kader kesehatan jiwa mencatat kegiatan di Kelurahan Gemah dengan format yang sudah disediakan oleh RSJ.

\section{Saran}

Kegiatan peran kader kesehatan jiwa perlu ditingkatkan ketrampilan cara melakukan deteksi dini dan cara pendokumentasian. Pihak 
Puskesmas setempat dalam hal ini Perawat CMHN untuk aktif dalam meningkatkan peran kader kesehatan jiwa. Meningkatkan pengetahuan dan ketrampilan dalam melakukan deteksi dini pada masyarakat yang sehat jiwa, resiko dan gangguan jiwa.

\section{DAFTAR PUSTAKA}

A, Kristiati., I, Rochmawati. \& A, Budiyanto. (2016). Pemberdayaan Kader Kesehatan Jiwa Untuk Deteksi Dini Anggota Masyarakat Yang Berisiko Melakukan Tindak Bunuh Diri. Proceding Konferensi Nasional VII Keperawatan Jiwa. Hal. 47.

WHO. (2016). Ikatan Dokter Indonesia. http://www.idionline.org/berita/harikesehatan-jiwa-sedunia-penyebabmunculnya-gangguan-kesehatan-jiwa diakses pada tanggal 9 Desember 2017.

Riset Kesehatan Dasar. (2017). Kementrian Kesehatan Republik Indonesia.

http://www.depkes.go.id/article/view/2014072 00002/naskah-undang-undang kesehatan-jiwa-disetujui.html diakses pada tanggal 9 Desember 2017.

Windarwati Dwi Heni., Lestari Retno., Kuswantoro., \& Hany Alfrina. (2013). Pemberdayaan Masyarakat Berbasis Keperawatan Kesehatan Jiwa Dalam Upaya Peningkatan Kualitas Kesehatan Jiwa Ibu dan Anak di Kecamatan Bantur dan Wager kabupaten Malang. Proceding Konferensi Nasional X Keperawatan Jiwa. Hal.133.

Nasir, Abdul., \& Abdul Muhith. (2011). Dasar-Dasar Keperawatan Jiwa. Jakarta: Salemba Medika.

Yosep, Iyus \& Sutini, Titin. (2007). Buku Ajar Keperawatan Jiwa dan Advance Mental Health Nursing. Bandung: PT Refika Aditama.

Setiadi. (2013). Konsep dan Praktik Penulisan Riset Keperawatan Edisi 2. Yogyakarta: Graha Ilmu.

Sugiyono. (2012). Metodologi Penelitian Kualitatif, Kuantitatif dan $R \& D$. Bandung: Alfabeta.
Keliat, Budi Anna., Novy, Helena C., \& Pipin, Farida. (2011). Manajemen Keperawatan Psikososial dan Kader Kesehatan Jiwa. Jakarta: EGC. . (2010). Manajemen Keperawatan Jiwa Komunitas Desa Siaga. Jakarta: EGC. 